\title{
COMBINATION OF TAGUCHI METHOD, MOORA AND COPRAS TECHNIQUES IN MULTI-OBJECTIVE OPTIMIZATION OF SURFACE GRINDING PROCESS
}

\author{
Nhu-Tung Nguyen \\ Faculty of Mechanical \\ Engineering, \\ Hanoi University of Industry, \\ Hanoi city, Vietnam
}

\author{
Do Duc Trung \\ Faculty of Mechanical \\ Engineering, \\ Hanoi University of Industry, \\ Hanoi city, Vietnamv
}

Crossref

$\mathrm{R} \partial \mathrm{AD} \equiv$

KOBSON

Taguchi, surface roughness, MRR

\section{Cite article:}

Nhu-Tung, N., \& Do, D. T. [2021]. Combination of taguchi method, moora and copras techniques in multi-objective optimization of surface grinding process. Journal of Applied Engineering Science, 19(2) 390 - 398. DOI:10.5937/jaes0-28702 


\title{
COMBINATION OF TAGUCHI METHOD, MOORA AND COPRAS TECHNIQUES IN MULTI-OBJECTIVE OPTIMIZATION OF SURFACE GRINDING PROCESS
}

\author{
Nhu-Tung Nguyen, Do Duc Trung* \\ Faculty of Mechanical Engineering, Hanoi University of Industry, Hanoi city, Vietnam
}

This study presentes a combination method of several optimization techniques and Taguchi method to solve the multi-objective optimization problem for surface grinding process of SKD11 steel. The optimization techniques that were used in this study were Multi-Objective Optimization on basis of Ratio Analysis (MOORA) and Complex Proportional Assessment (COPRAS). In surface grinding process, two parameters that were chosen as the evaluation creterias were surface roughness (Ra) and material removal rate (MRR). The orthogonal Taguchi $L_{16}$ matrix was chosen to design the experimental matrix with two input parameters namely workpiece velocity and depth of cut. The two optimization techniques that mentioned above were applied to solve the multi-objective optimization problem in the grinding process. Using two above techniques, the optimized results of the cutting parameters were the same. The optimal values of workpiece velocity and cutting depth were $20 \mathrm{~m} / \mathrm{min}$ and $0.02 \mathrm{~mm}$, respectively. Corresponding to these optimal values of the workpiece velocity and cutting depth, the surface roughness and material removal rate were $1.16 \mu \mathrm{m}$ and $86.67 \mathrm{~mm}^{3} / \mathrm{s}$. These proposed techniques and method can be used to improve the quality and effectiveness of grinding processes by reducing the surface roughness and increasing the material removal rate.

Key words: multi-objective optimization, surface grinding, SKD11 Steel, MOORA, COPRAS, Taguchi, surface roughness, MRR

\section{INTRODUCTION}

In the machining methods, grinding method are the most common method to machine the surfaces that requires high precision and high surface gloss. The efficiency of the grinding process is evaluated through many parameters such as surface roughness, material removal rate (MRR), cutting forces, cutting heat, system vibrations, ... Many studies have been done to determine the optimum value of the machining parameters to achieve one or more objectives.

Mahajan et al. [1] determined the optimal value of wheel grit size, the grinding wheel speed, the feed rate per revolution, and depth of cut in surface grinding process of D2 steel. Taguchi method was applied to design and optimize the machining surface roughness and material removal rate. To obtain the minimum value of surface roughness, the optimal value of wheel grit size, the grinding wheel speed, the feed rate per revolution, and depth of cut were 46 (mesh), 2300 (rev/min), 0.834 (mm/rev), and $0.05(\mathrm{~mm})$, respectively. Besides, to obtain the maximum value of MRR, the optimal value of wheel grit size, the grinding wheel speed, the feed rate per revolution, and depth of cut were 36 (mesh), 1650 (rev/min), 0.834 $(\mathrm{mm} / \mathrm{rev})$, and $0.075(\mathrm{~mm})$, respectively. However, this method has not yet given a set of values of input parameters to ensure simultaneously the minimum value of surface roughness and maximum value of MRR.

Rai et al. [2] used Taguchi method to optimize the sur- face grinding process of AISI410 steel. The wheel grit size, the feed rate per revolution, and depth of cut were chosen the input parameters to design the experimental matrix. The aim of this study was determination of the input parameters to ensure the average surface roughness and mean square of surface roughness having the minimum values. Using this method, the average surface roughness and mean square of surface roughness have also the minimum values when the wheel grit size, the feed rate per revolution, and depth of cut were 54 (mesh), $0.5(\mathrm{~mm} / \mathrm{rev})$, and $0.06(\mathrm{~mm})$, respectively.

Atish et al. [3] used Taguchi to optimize the surface grinding process of the mild steel. The aim of this study was determination of values of the depth of cut, the workpiece velocity, and cross feed rate to achieve the minimum value of surface roughness and maximum of MRR. This study found that to obtain the minimum of surface roughness, the depth of cut, the workpiece velocity, and cross feed rate were $0.1(\mathrm{~mm}), 20$ (strokes $/ \mathrm{min}$ ), and 10 (strokes/min), respectively. To obtain the maxinmum of MRR, the depth of cut, the workpiece velocity, and cross rate were $0.1(\mathrm{~mm}), 30$ (strokes/min), and 30 (strokes/ min), respectively.

Aravind et al. [4] combined the Taguchi method and response surface method (RSM) to optimize the surface grinding process of ASIS 1035 steel. The wheel grain size, the grinding wheel speed, depth of cut, and feed rate were selected as the input parameters to design the experimental matrix. This study showed that to obtain 
the minimum values of both $\mathrm{Ra}$ and $\mathrm{Rz}$, the wheel grain size, the grinding wheel speed, depth of cut, and feed rate were 54 (mesh), $0.05(\mathrm{~mm})$, and 0.45 ( $\mathrm{mm} / \mathrm{stroke})$, respectively.

Hamid Reza FAZLI SHAHRI et al. [5] combined Taguchi method and regression analysis to optimize the surface grinding process of AISI 1045 AISI 1045. This study showed that to achieve the maximum of machining surface hardness, the grinding wheel must be fine dressed, and the optimal values of depth of cut, cutting velocity, workpiece velocity, cross feed were $0.03(\mathrm{~mm}), 32(\mathrm{~m} / \mathrm{s})$, $10(\mathrm{~m} / \mathrm{min})$, and $5(\mathrm{~mm} / \mathrm{rev})$, respectively.

Prashant et el. [6] combined the Taguchi method and grey relational analysis (GRA) technique to optimize the surface grinding process of EN8 steel. The parameters that were selected as the input parameters were depth of cut, type of lubricant, feed rate, grinding wheel speed, coolant flow rate, and nanoparticle size. This study showed that to obtain the minimum of surface roughness, the type of lubricant was the water containing the CuO particles with the grain size of $100(\mathrm{~nm})$, concentration of $2 \%$, and flow of $5(\mathrm{ml} / \mathrm{min})$, and the depth of cut, feed rate, grinding wheel speed were $5(\mu \mathrm{m}), 2000(\mathrm{~mm} /$ $\min )$, and $35(\mathrm{~m} / \mathrm{s})$, respectively.

Luu Anh Tung et al. [7] also combined Taguchi method and GRA to determine the optimal values of the grinding wheel dressing parameters in grinding process of $9 \mathrm{CrSi}$ tool steel. The purpose of this study was assurance of the minimum value of machining surface roughness and minimum value of the flatness tolerance. In this study, the optimal values of the dressing parameters were determined including: The coarse dressing depth was $0.025(\mathrm{~mm})$, the coarse dressing times were 3 times, the fine dressing depth was $0.005(\mathrm{~mm})$, the fine dressing times were 2 times, and the dressing feed rate was 1.6 (m/min).

In other study, the multi-objective optimization in surface grinding process of $90 \mathrm{CrSi}$ tool steel was also performed by Nguyen Thi Hong et al. [8]. This study aimed to determine the dressing parameters to simultaneously ensure the minimum values of surface roughness and tangential cutting force, and maximum value of tool life. In this study, Taguchi method and GRA were combined to determine the optimal values of dressing parameters as following. The coarse dressing depth was $0.015(\mathrm{~mm})$, the coarse dressing times were 2 (times), the fine dressing depth was $0.005(\mathrm{~mm})$, the non-feeding dressing times were 3 (times), and the dressing feed rate was $1.6(\mathrm{~m} /$ $\min )$.

The combination of Taguchi method and GRA was also applied to solve the multi-objective optimization problem in the surface grinding process of AISI D2 steel [9]. In this study, three different coolant conditions were applied in surface grinding process including dry conditions, flood cooling condition, and minimum quantity lubrication (MQL) condition. This study showed that to simultaneously ensure the minimum values of machining surface roughness, cutting heat, and normal cutting forces, the grinding process was performed with a cutting depth of 15 $(\mu \mathrm{m})$, a workpiece velocity of $3(\mathrm{~m} / \mathrm{min})$, cutting velocity of $25(\mathrm{~m} / \mathrm{s})$, and with flow rate $250(\mathrm{~mL} / \mathrm{h})$ of MQL condition.

Prashant J. Patil et al. [10] also combined Taguchi method and GRA to solve the multi-objective optimization problem in surface grinding process of EN-24 steel in MQL condition. The input parameters that were selected in this study included the nanoparticles in the lubricating solution (Al2O3, CuO, water), the concentration of particles, particle size, flow rate of solution, depth of cut, feed rate, and cutting velocity. The obtained results showed that to simultaneously achieve the minimum values of mormal cutting force, tangential cutting force, and cutting heat, the grinding process must be performed in the lubricating solution using $\mathrm{CuO}$ nanoparticle with a concentration of $2 \%$, a nanoparticle size of $100(\mathrm{~nm})$, a coolant flow rate of 5 ( $\mathrm{ml} /$ minute), and with a cutting depth of 5 $(\mu \mathrm{m})$, a feed rate of $2000(\mathrm{~mm} / \mathrm{min})$, and a grinding wheel speed $35(\mathrm{~m} / \mathrm{s})$.

The combination of Taguchi method and GRA to solve the multi-objective optimization problem in grinding process of OCR12VM material was performed by Hendri Jumianto et al. [11]. This study showed that to ensure the minimum values of system vibrations, the cutting velocity, workpiece velocity, and cross feed rate were 3000 (rpm), 11 ( $\mathrm{mm} / \mathrm{s})$, and 5 ( $\mathrm{mm} /$ stroke), respectively.

From above studies, it shows that the Taguchi method has been successfully applied in solving the optimization of the surface grinding process in many specific cases. Among published studies, the cutting parameters are often chosen as the input parameters for the experimental process. This issue could be explained that the adjustment of these parameters during machining is more easily done by the operator than by adjusting other parameters such as the rigidity of the machine system, the vibrating factors transmitted into the system, etc. However, with each specific case about the machining material, the optimal values of cutting parameters were different. So, for each machining material and each specific machining condition, the experimental and optimization studies must be performed under specific conditions. Besides, if only using Taguchi method, only one evaluation criteria is optimized (the single objective optimization), if the multi-objective optimization problem is solved, the Taguchi method must be combined with other methods or techniques.

MOORA and COPRAS are two of the famous optimization methods that were applied into different research fields. Gadakh [12] combined Taguchi and MOORA technique to optimize the cutting parameters of the milling process. The purpose of this study was determination of the optimal values of spindle speed, feed rate per flute, tool diameter, tool nose radius, and the machining time to ensure the minimum of the tool wear, and to ensure the maximum of MRR.

Mesran et al. [13] applied the MOORA technique to in- 
vestigate the division of the students into each class when entering the universities. This study proposed the best method to divide the students into the class based on the parameters of each student (UN Average Score, Psychotest Value, IPA Value, Mathematics Value, Interview Value). Nguyen et al. [14] used the MOORA to optimize the Powder mixed electrical discharge machining (PMEDM). The aim of this study to determine the optimal values of the workpiece material, tool material, polarity, peak current, pulse-on-time, pulse-off-time, and titanium powder concentration to ensure the minimum values of surface roughness and electrode wear. Tran et al. [15] applied MOORA and COPRAS techniques to determine the optimal values of the materials (straw, corn cobs, sawdust, rice bran, and $\mathrm{CaCO} 3$ ) for growing mushrooms, and so on. However, up to now, there have not been any published studies on the application of these two techniques to solve the multi-objective optimization problem in the machining process in general or the surface grinding processes in particular.

Surface roughness has a significant influence on the workability and life of the product. While MRR is a parameter that reflects machining productivity, energy consumption, grinding wheel consumption, so the efficiency of grinding process also can be evaluated through this parameter. Therefore, these two parameters are often chosen as indicators of evaluating the efficiency of grinding processes in general and the surface grinding process in particular.

In this study, SKD11 steel was grinded on a surface grinder. The experiments were designed according to the Taguchi method including 16 experiments. In which, the workpiece velocity and cutting depth were selected as the input parameters for each experiment. The surface roughness and MRR were chosen as the two output parameters. Two techniques MOORA and COPRAS have been applied to solve the multi-objective optimization problem. The results showed that these techniques have determined the same set of values of workpiece velocity and depth of cut to ensure the minimum value of surface roughness and maximum value of MRR. The two techniques MOORA and COPRAS not only successfully applied in solving the multi-objective optimization problem of the surface grinding process in this study, but also opened up a very potential research direction in multi-objective optimization of other machining processes.

\section{EXPERIMENTAL METHOD}

\section{Experimental system}

The experiments were conducted in the surface grinding APSG-820/2A machine. The grinding wheel aluminum oxide APSG-820/2A was used in this study. The workpiece material that was used in the experimental process was heat treated SKD11 with the hardness of $60 \mathrm{HRC}$. The length, width, and height of workpiece were $80(\mathrm{~mm})$, $40(\mathrm{~mm})$, and $10(\mathrm{~mm})$, respectively. The surface roughness tester SJ-301 (Japan) was used to measure the surface roughness of machining parts. Each experiment, the surface roughness was measured at least three consecutive times. The average value of surface roughness was used for evaluation and analysis process.

The material removal rate RMM was calculated by equation $M R R=v_{w} \times b \times t\left(\mathrm{~mm}^{3} / \mathrm{s}\right)$. Where $v_{w}, b$, and $t$ are the workpiece velocity $(\mathrm{m} / \mathrm{s})$, the width of the grinding wheel $(\mathrm{mm})$, and the depth of cut $(\mathrm{mm})$, respectively.

\section{Experimental design}

The Taguchi method was applied to design the experimental matrix. The cutting parameters that were chosen as the input parameters were workpiece velocity and depth of cut. The orthogonal $L_{16}$ matrix with 16 experiments was used and listed in Table 1.

Table 1: Experimental matrix

\begin{tabular}{|c|c|c|}
\hline No. & $\begin{array}{c}v_{w} \\
(\mathrm{~m} / \mathrm{min})\end{array}$ & $\begin{array}{c}t \\
(\mathrm{~mm})\end{array}$ \\
\hline 1 & 5 & 0.005 \\
\hline 2 & 5 & 0.001 \\
\hline 3 & 5 & 0.015 \\
\hline 4 & 5 & 0.002 \\
\hline 5 & 10 & 0.005 \\
\hline 6 & 10 & 0.001 \\
\hline 7 & 10 & 0.015 \\
\hline 8 & 10 & 0.002 \\
\hline 9 & 15 & 0.005 \\
\hline 10 & 15 & 0.001 \\
\hline 11 & 15 & 0.015 \\
\hline 12 & 15 & 0.002 \\
\hline 13 & 20 & 0.005 \\
\hline 14 & 20 & 0.001 \\
\hline 15 & 20 & 0.015 \\
\hline 16 & 20 & 0.002 \\
\hline
\end{tabular}

\section{Grinding conditions}

The experiments were conducted with the controllable factors in Table 1 and with the grinding conditions as following:

- The cutting velocity: $26 \mathrm{~m} / \mathrm{s}$.

- The dressing depth of cut: $0.01 \mathrm{~mm}$.

- The dressing feed rate: $100 \mathrm{~mm} / \mathrm{min}$

- Cooling fluid: emulsion 10\%, overflow irrigation method.

\section{MULTI-OBJECTIVE OPTIMIZATION PROCESS USING MOORA AND COPRAS TECHNIQUES}

\section{Multiple-Criteria Decision Making (MCDM)}

The multiple criteria decision making - MCDM can be used to select the best solution from the solutions $A=\left\{A_{1}, A_{2}, \ldots, A_{m}\right\}$ based on the criterias $C=\left\{C_{1}, C_{2}, \ldots, C_{n}\right\}$. 
In which, each crireria $C_{j}$ is assigned with a weight $\mathrm{w}_{\mathrm{j}}(\mathrm{j}=1,2, \ldots, \mathrm{n})$, so that $\sum_{j=1}^{n} w_{j}=1$. A MCDM problem can be presented by the matrix $D=\left[d_{i j}\right]_{m \times n}[16]$.

$$
\begin{gathered}
A_{1} \\
A_{2} \\
\vdots \\
A_{3}
\end{gathered}\left[\begin{array}{cccc}
d_{11} & d_{12} & d_{1 n} & d_{1 n} \\
d_{21} & d_{22} & d_{2 n} & d_{2 n} \\
\vdots & \vdots & \vdots & \vdots \\
d_{m 1} & d_{m 2} & d_{m n} & d_{m n}
\end{array}\right]
$$

where $d_{i j} \in R^{+}$with $\mathrm{i}=1,2, \ldots, \mathrm{m}$ and $\mathrm{j}=1,2, \ldots, \mathrm{n}$.

In this study, in the MOORA and COPRAS techniques, the weights were calculated using measurement of Entropy, because this method can get the high accuracy. The steps of the weight calculation process will be performed as following $[17,18]$ :

Step 1: Calculating the values $p_{i j}$ with $\mathrm{i}=1,2, \ldots, \mathrm{m}$ and $\mathrm{j}=1,2, \ldots, \mathrm{n}$ using Eq. (1).

$$
p_{i j}=\frac{d_{i j}}{m+\sum_{i=1}^{m} d_{i j}^{2}}
$$

Step 2: Calculating the measurement entropy $e_{j}$ of each criterion $C_{j}$ with $\mathrm{j}=1,2, \ldots, \mathrm{n}$ by Eq. (2).

$$
e_{j}=-\sum_{i=1}^{m}\left[p_{i j} \ln \left(p_{i j}\right)\right]-\left(1-\sum_{i=1}^{m} p_{i j}\right) \times \ln \left(1-\sum_{i=1}^{m} p_{i j}\right)
$$

Step 3: Calculating the weight $w_{j}$ of each criterion $C_{j}$ with $\mathrm{j}=1,2, \ldots, \mathrm{n}$ by Eq. (3).

$$
w_{j}=\frac{1-e_{j}}{\sum_{j=1}^{n}\left(1-e_{j}\right)}
$$

\section{MOORA technique}

MOORA $\left(1-e_{j}\right)$ technique was introduced the first time in 2004 by Brauers [19]. This multi-objective optimization technique can be successfully appliec to solve the complex decision problems in the production environment with the together conflicting objectives. The MOORA technique includes the steps as following:

Step 1: Calculating the values $p_{i j}$ with $\mathrm{i}=1,2, \ldots, \mathrm{m}$ and $\mathrm{j}=1,2, \ldots, \mathrm{n}$ using Eq. (1).

Step 2: Calculating the measurement entropy $\mathrm{e} j \mathrm{j}$ of each criterion $C_{j}$ with $\mathrm{j}=1,2, \ldots, \mathrm{n}$ by Eq. (2).

Step 3: Calculating the weight $w_{j}$ of each criterion $C_{j}$ with $\mathrm{j}=1,2, \ldots, \mathrm{n}$ by Eq. (3).

Step 4: Calculating the standardized matrix $\left[X_{i j}\right]_{m \times n}$ with $\mathrm{i}$ $=1,2, \ldots, \mathrm{m}$ and $\mathrm{j}=1,2, \ldots, \mathrm{n}$ by Eq. (4)

$X=\left[X_{i j}\right]_{m \times n}$ với $X_{i j}=\frac{d_{i j}}{\sqrt{\sum_{i=1}^{m} d_{i j}^{2}}}$

Step 5: Calculating the decision matrix after standardizing with the weight $W=\left[W_{i j}\right]_{m \times n}$ with $\mathrm{i}=1,2, . ., \mathrm{m}$ and $\mathrm{j}=1$, $2, \ldots, n$ by Eq. (5).

$W_{i j}=w_{j} \times x_{i j}$
Step 6: Calculating $P_{i}$ and $R_{i}$ by Eq. (6) and Eq. (7).

$P_{i}=\frac{1}{|B|} \sum_{j \in B} W_{i j}$

$R_{i}=\frac{1}{|N B|} \sum_{j \in N B} W_{i j}$

where $B$ and $N B$ are the set of benefit criteria and the set of non-beneficial criteria with $\mathrm{i}=1,2, \ldots, \mathrm{m}$.

Step 7: Calculating the priority value with $\mathrm{i}=1,2, \ldots, \mathrm{m}$ by Eq. (8).

$Q_{i}=P_{i}-R_{i}$

Step 8: Ranking the solutions $A_{k}>A_{i}$ if $Q_{k}<Q_{i}$ with i, $\mathrm{k}=$ $1,2, \ldots, \mathrm{m}$.

\section{COPRAS technique}

COPRAS technique was introduced by Zavadskas et al. [18]. This is a famous multi-objective optimization method. The COPRAS technique includes the steps as following:

Step 1: Calculating the values $p_{i j}$ with $\mathrm{i}=1,2, \ldots, \mathrm{m}$ and $\mathrm{j}=1,2, \ldots, \mathrm{n}$ using Eq. (1).

Step 2: Calculating the measurement entropy $e_{j}$ of each criterion $C_{j}$ with $\mathrm{j}=1,2, \ldots, \mathrm{n}$ by Eq. (2).

Step 3: Calculating the weight $w_{j}$ of each criterion $C_{j}$ with $\mathrm{j}=1,2, \ldots, \mathrm{n}$ by Eq. (3).

Step 4: Calculating the standardized matrix $\left[X_{i j}\right]_{m \times n}$ with $\mathrm{i}$ $=1,2, \ldots, \mathrm{m}$ and $\mathrm{j}=1,2, \ldots, \mathrm{n}$ by Eq. (9)

$X_{i j}=\frac{d_{i j}}{\sum_{i=1}^{m} d_{i j}}$

Step 5: Calculating the decision matrix after standardizing with the weight $W=\left[W_{i j}\right]_{m \times n}$ with $\mathrm{i}=1,2, \ldots, \mathrm{m}$ and $\mathrm{j}=1,2, \ldots, \mathrm{n}$ by Eq. (10).

$W_{i j}=w_{j} \times d_{i j}$

Step 6: Calculating $P_{i}$ and $R_{i}$ by Eq. (11) and Eq. (12).

$P_{i}=\frac{1}{|B|} \sum_{j \in B} W_{i j}$

$R_{i}=\frac{1}{|N B|} \sum_{j \in N B} W_{i j}$

Step 7: Calculating the priority value with $\mathrm{i}=1,2, \ldots, \mathrm{m}$ by Eq. (13).

$$
Q_{i}=P_{i}+\frac{\sum_{i=1}^{m} R_{i}}{R_{i} \times \sum_{i=1}^{m} \frac{1}{R_{i}}}
$$

Step 8: Ranking the solutions $A_{k}>A_{i}$ if $Q_{k}<Q_{i}$ with i, $\mathrm{k}=$ $1,2, \ldots, \mathrm{m}$. 


\section{MULTI-OBJECTIVE OPTIMIZATION RESULTS OF SURFACE GRINDING PROCESS OF SKD11 STEEL}

\section{Experimental results}

The experiments were conducted according to the experimental matrix in Table 1. The experimental results were listed in Table 2. To facilitate for the using of the mathematical symbols when optimizing according to MOORA and COPRAS techniques, the surface roughness criterion and the MRR criterion were set as $\mathrm{C} 1$ and C2 as presented in Table 3.

Table 2: Experimental results

\begin{tabular}{|c|c|c|c|c|}
\hline No. & $\begin{array}{c}\mathrm{v}_{\mathrm{w}} \\
(\mathrm{m} / \mathrm{min})\end{array}$ & $\begin{array}{c}\mathrm{t} \\
(\mathrm{mm})\end{array}$ & $\begin{array}{c}\mathrm{Ra} \\
(\mu \mathrm{m})\end{array}$ & $\begin{array}{c}\mathrm{MRR} \\
\left(\mathrm{mm}^{3} / \mathrm{s}\right)\end{array}$ \\
\hline 1 & 5 & 0.005 & 0.59 & 5.42 \\
\hline 2 & 5 & 0.001 & 0.66 & 1.08 \\
\hline 3 & 5 & 0.015 & 0.53 & 16.25 \\
\hline 4 & 5 & 0.002 & 0.38 & 21.67 \\
\hline 5 & 10 & 0.005 & 0.85 & 10.83 \\
\hline 6 & 10 & 0.001 & 0.83 & 2.17 \\
\hline 7 & 10 & 0.015 & 0.77 & 32.50 \\
\hline 8 & 10 & 0.002 & 0.64 & 43.33 \\
\hline 9 & 15 & 0.005 & 1.01 & 16.25 \\
\hline 10 & 15 & 0.001 & 1.22 & 3.25 \\
\hline 11 & 15 & 0.015 & 1.02 & 48.75 \\
\hline 12 & 15 & 0.002 & 0.90 & 65.00 \\
\hline 13 & 20 & 0.005 & 1.23 & 21.67 \\
\hline 14 & 20 & 0.001 & 1.29 & 4.33 \\
\hline 15 & 20 & 0.015 & 1.26 & 65.00 \\
\hline 16 & 20 & 0.002 & 1.16 & 86.67 \\
\hline
\end{tabular}

Table 3: Surface roughness and MRR with the different values of input parameters

\begin{tabular}{|c|c|c|}
\hline No. & C1 & C2 \\
\hline A1 & 0.59 & 5.42 \\
\hline A2 & 0.66 & 1.08 \\
\hline A3 & 0.53 & 16.25 \\
\hline A4 & 0.38 & 21.67 \\
\hline A5 & 0.85 & 10.83 \\
\hline A6 & 0.83 & 2.17 \\
\hline A7 & 0.77 & 32.50 \\
\hline A8 & 0.64 & 43.33 \\
\hline A9 & 1.01 & 16.25 \\
\hline A10 & 1.22 & 3.25 \\
\hline A11 & 1.02 & 48.75 \\
\hline A12 & 0.90 & 65.00 \\
\hline A13 & 1.23 & 21.67 \\
\hline A14 & 1.29 & 4.33 \\
\hline A15 & 1.26 & 65.00 \\
\hline A16 & 1.16 & 86.67 \\
\hline
\end{tabular}

\section{The optimized results using MOORA technique}

From the data in Table 3, MOORA technique was used to calculate the values as following:

Step 1: Calculating the values $p_{i j}$ by Eq. (1). The calculated results were listed in Table 4.

Step 2: Calculating the values $e_{i}$ by Eq. (2). The calculated results were listed in Table 5.

Step 3: Calculating the values $w_{\text {f }}$ by Eq. (3). The calculated results were also listed in Table 5 .

Step 4: Calculating the matrix $X=\left[X_{i j}\right]_{m \times n}$ by Eq. (4). The calculated results were listed in Table 6 .

Step 5: Calculating the matrix $W$ by Eq. (5). The calculated results were listed in Table 7.

Step 6: Calculating the values $P$ and $R i$ by Eq. (6) and Eq. (7). The calculated results were listed in Table 8.

Step 7: Calculating the values $Q_{i}$ by Eq. (8). The calculated results were also listed in Table 8.

The calculated results from Table 8 showed that the solution $A_{16}$ was the best solution in 16 solutions. If considering only the surface roughness criteria or only the MRR, $A_{16}$ is not the best solution (Table 2). However, when considering the two parameters of surface roughness and MRR at the same time, this solution was considered to be the best solution.

Table 4: Value of $p_{i j}$

\begin{tabular}{|c|c|c|}
\hline No. & C1 & C2 \\
\hline A1 & 0.011377 & 0.000236 \\
\hline A2 & 0.014478 & $4.72 \mathrm{E}-05$ \\
\hline A3 & 0.009303 & 0.000708 \\
\hline A4 & 0.004826 & 0.000945 \\
\hline A5 & 0.024013 & 0.000472 \\
\hline A6 & 0.022727 & $9.45 \mathrm{E}-05$ \\
\hline A7 & 0.019925 & 0.001417 \\
\hline A8 & 0.013682 & 0.001889 \\
\hline A9 & 0.034146 & 0.000708 \\
\hline A10 & 0.049468 & 0.000142 \\
\hline A11 & 0.034506 & 0.002125 \\
\hline A12 & 0.027017 & 0.002834 \\
\hline A13 & 0.050043 & 0.000945 \\
\hline A14 & 0.054886 & 0.000189 \\
\hline A15 & 0.053023 & 0.002834 \\
\hline A16 & 0.044805 & 0.003779 \\
\hline
\end{tabular}

Table 5: Weight of the criterias

\begin{tabular}{|c|c|c|}
\hline & C1 & C2 \\
\hline Entropy & 1.911441 & 0.140969 \\
\hline Weigth & 17.39053 & -16.3905 \\
\hline
\end{tabular}


Table 6: Standardized matrix using MOORA technique

\begin{tabular}{|c|c|c|}
\hline No. & C1 & C2 \\
\hline A1 & 0.1559 & 0.0358 \\
\hline A2 & 0.1758 & 0.0072 \\
\hline A3 & 0.1410 & 0.1073 \\
\hline A4 & 0.1015 & 0.1431 \\
\hline A5 & 0.2265 & 0.0716 \\
\hline A6 & 0.2203 & 0.0143 \\
\hline A7 & 0.2063 & 0.2147 \\
\hline A8 & 0.1709 & 0.2862 \\
\hline A9 & 0.2700 & 0.1073 \\
\hline A10 & 0.3250 & 0.0215 \\
\hline A11 & 0.2715 & 0.3220 \\
\hline A12 & 0.2402 & 0.4293 \\
\hline A13 & 0.3269 & 0.1431 \\
\hline A14 & 0.3424 & 0.0286 \\
\hline A15 & 0.3365 & 0.4293 \\
\hline A16 & 0.3093 & 0.5725 \\
\hline
\end{tabular}

Table 7: Combination of standardized matrix using MOORA technique and weight

\begin{tabular}{|c|c|c|}
\hline No. & C1 & C2 \\
\hline A1 & 10.1746 & -88.7819 \\
\hline A2 & 11.4777 & -17.7564 \\
\hline A3 & 9.2007 & -266.3456 \\
\hline A4 & 6.6270 & -355.1275 \\
\hline A5 & 14.7820 & -177.5638 \\
\hline A6 & 14.3808 & -35.5128 \\
\hline A7 & 13.4649 & -532.6913 \\
\hline A8 & 11.1578 & -710.2550 \\
\hline A9 & 17.6270 & -266.3456 \\
\hline A10 & 21.2164 & -53.2691 \\
\hline A11 & 17.7198 & -799.0369 \\
\hline A12 & 15.6793 & -1065.3825 \\
\hline A13 & 21.3393 & -355.1275 \\
\hline A14 & 22.3480 & -71.0255 \\
\hline A15 & 21.9654 & -1065.3825 \\
\hline A16 & 20.1916 & -1420.5100 \\
\hline
\end{tabular}

Table 8. Calculated results of Pi, Ri, Qi and the ranked results using MOORA technique

\begin{tabular}{|c|c|c|c|c|}
\hline No. & $\mathrm{Pi}$ & $\mathrm{Ri}$ & $\mathrm{Qi}$ & Ranking \\
\hline $\mathrm{A} 1$ & 10.1746 & -88.7819 & 98.9565 & 12 \\
\hline $\mathrm{A} 2$ & 11.4777 & -17.7564 & $\mathbf{2 9 . 2 3 4 1}$ & 16 \\
\hline $\mathrm{A} 3$ & 9.2007 & -266.3456 & 275.5464 & 10 \\
\hline $\mathrm{A} 4$ & 6.6270 & -355.1275 & 361.7545 & 8 \\
\hline $\mathrm{A} 5$ & 14.7820 & -177.5638 & 192.3457 & 11 \\
\hline $\mathrm{A} 6$ & 14.3808 & -35.5128 & 49.8936 & 15 \\
\hline $\mathrm{A} 7$ & 13.4649 & -532.6913 & 546.1562 & 6 \\
\hline $\mathrm{A} 8$ & 11.1578 & -710.2550 & 721.4128 & 5 \\
\hline $\mathrm{A} 9$ & 17.6270 & -266.3456 & 283.9727 & 9 \\
\hline $\mathrm{A} 10$ & 21.2164 & -53.2691 & 74.4856 & 14 \\
\hline $\mathrm{A} 11$ & 17.7198 & -799.0369 & 816.7567 & 4 \\
\hline $\mathrm{A} 12$ & 15.6793 & -1065.3825 & 1081.0618 & 3 \\
\hline $\mathrm{A} 13$ & 21.3393 & -355.1275 & 376.4668 & 7 \\
\hline $\mathrm{A} 14$ & 22.3480 & -71.0255 & 93.3735 & 13 \\
\hline $\mathrm{A} 15$ & 21.9654 & -1065.3825 & 1087.3479 & 2 \\
\hline $\mathrm{A} 16$ & 20.1916 & -1420.5100 & $\mathbf{1 4 4 0 . 7 0 1 6}$ & 1 \\
\hline
\end{tabular}

\section{The optimized results using COPRAS technique}

From the data in Table 3, COPRAS technique was applied according to the steps in above section. The results were calculated and listed in Table 9, Table 10, and Table 11.

The calculated results from Table 11 also showed that the solution $\mathrm{A} 16$ was the best solution in 16 solutions. The ranking order of the solutions in Table 11 also co- incided with the ranking order of solutions in Table 8. Thus, in this case, the MOORA and the COPRAS techniques gave a unified result when determining the optimal solution. That further confirms the correctness of the implemented methods. So, in surface grinding process of KSD11 steel, to ensure the minumum value of surface roughness and maximum value of material removal rate, the optimal values of the workpiece velocity and cutting depth were $20 \mathrm{~m} / \mathrm{min}$ and $0.02 \mathrm{~mm}$. 
Table 9: Standardized matrix using COPRAS technique

\begin{tabular}{|c|c|c|}
\hline No. & C1 & C2 \\
\hline A1 & 0.0415 & 0.0002 \\
\hline A2 & 0.0468 & 0.0000 \\
\hline A3 & 0.0376 & 0.0007 \\
\hline A4 & 0.0270 & 0.0009 \\
\hline A5 & 0.0603 & 0.0005 \\
\hline A6 & 0.0587 & 0.0001 \\
\hline A7 & 0.0550 & 0.0014 \\
\hline A8 & 0.0455 & 0.0019 \\
\hline A9 & 0.0719 & 0.0007 \\
\hline A10 & 0.0866 & 0.0001 \\
\hline A11 & 0.0723 & 0.0021 \\
\hline A12 & 0.0640 & 0.0028 \\
\hline A13 & 0.0871 & 0.0009 \\
\hline A14 & 0.0912 & 0.0002 \\
\hline A15 & 0.0897 & 0.0028 \\
\hline A16 & 0.0824 & 0.0038 \\
\hline
\end{tabular}

Table 10: Combination of Standardized matrix using COPRAS technique

\begin{tabular}{|c|c|c|}
\hline No. & C1 & C2 \\
\hline A1 & 10.17462 & -88.7819 \\
\hline A2 & 11.47775 & -17.7564 \\
\hline A3 & 9.20075 & -266.346 \\
\hline A4 & 6.626951 & -355.128 \\
\hline A5 & 14.78195 & -177.564 \\
\hline A6 & 14.38081 & -35.5128 \\
\hline A7 & 13.46491 & -532.691 \\
\hline A8 & 11.15776 & -710.255 \\
\hline A9 & 17.62704 & -266.346 \\
\hline A10 & 21.21645 & -53.2691 \\
\hline A11 & 17.71979 & -799.037 \\
\hline A12 & 15.6793 & -1065.38 \\
\hline A13 & 21.33934 & -355.128 \\
\hline A14 & 22.34799 & -71.0255 \\
\hline A15 & 21.9654 & -1065.38 \\
\hline A16 & 20.19156 & -1420.51 \\
\hline
\end{tabular}

Table 11: Calculated results of Pi, Ri, Qi and the ranked results using using COPRAS technique

\begin{tabular}{|c|c|c|c|c|}
\hline No. & $\mathrm{Pi}$ & $\mathrm{Ri}$ & $\mathrm{Qi}$ & Ranking \\
\hline A1 & 10.17462 & -88.7819 & -520.6382 & 12 \\
\hline A2 & 11.47775 & -17.7564 & $\mathbf{- 2 6 4 2 . 5 8 6 1}$ & 16 \\
\hline A3 & 9.20075 & -266.346 & -167.7368 & 10 \\
\hline A4 & 6.626951 & -355.128 & -126.0762 & 8 \\
\hline A5 & 14.78195 & -177.564 & -250.6244 & 11 \\
\hline A6 & 14.38081 & -35.5128 & -1312.6511 & 15 \\
\hline A7 & 13.46491 & -532.691 & -75.0039 & 6 \\
\hline A8 & 11.15776 & -710.255 & -55.1938 & 5 \\
\hline A9 & 17.62704 & -266.346 & -159.3106 & 9 \\
\hline A10 & 21.21645 & -53.2691 & -863.4715 & 14 \\
\hline A11 & 17.71979 & -799.037 & -41.2594 & 4 \\
\hline A12 & 15.6793 & -1065.38 & -28.5551 & 3 \\
\hline A13 & 21.33934 & -355.128 & -111.3639 & 7 \\
\hline A14 & 22.34799 & -71.0255 & -641.1680 & 13 \\
\hline A15 & 21.9654 & -1065.38 & -22.2690 & 2 \\
\hline A16 & 20.19156 & -1420.51 & -12.9842 & 1 \\
\hline
\end{tabular}

\section{CONCLUSIONS}

This study was performed using Taguchi method, MOORA and COPRAS techniques to solve the multi-objective optimization problem for surface grinding process of SKD11 steel. The conclusions of this study were drawn as following:

- Taguchi method, MOORA and COPRAS techniques were successfully applied to solve the multi-objec- tive optimization problem for surface grinding process of SKD11 steel. Using these above techniques, the optimized results of the cutting parameters were the same.

- The optimal workpiece velocity and cutting depth were $20 \mathrm{~m} / \mathrm{min}$ and $0.02 \mathrm{~mm}$. Corresponding to these optimal values of the workpiece velocity and cutting depth, the surface roughness and material removal 
rate were $1.16 \mu \mathrm{m}$ and $86.67 \mathrm{~mm}^{3} / \mathrm{s}$, respectively.

- $\quad$ hese proposed techniques and method can be used to improve the quality and effectiveness of grinding processes by reducing the surface roughness and increasing the material removal rate.

\section{ACKNOWLEDGEMENT}

The authors thank Hanoi University of Industry for the support during the implementation of this study.

\section{REFERENCES}

1. Mahajan, T. V., Nikalje, A. M., \& Supale, J. P. (2015). Optimization of surface grinding process parameters for AISI D2 steel. Int J Eng Sci Res Technol, 4(7), 944-949.

2. Rajesh Rai P, Vijaykumar H K. (2019). Optimization of Process Parameters in Surface Grinding for AISI 410 by Taguchi Technique, AIP Conference Proceedings, 2080(050001), 1-6. doi:https://doi. org/10.1063/1.5092929

3. Atish. B. Mane., Subhash Nagwase, Sunilkumar Rajaram Patil. (2020). Optimization of Surface Grinding Process Parameters using Taguchi Method, A Journal of Composition Theory, 13(5), 78-87. doi:20.18001.AJCT.2020.V13I5.20.124377

4. Aravind, M., and Periyasamy, D. S. (2014). Optimization of Surface Grinding Process Parameters By Taguchi Method And Response Surface Methodology, International Journal of Engineering Research \& Technology, 3(5), 1721-2727. https://www.ijert. org/optimization-of-surface-grinding-process-parameters-by-taguchi-method-and-response-surface-methodology

5. SHAHRI, H. R. F., Akbari, A. A., Mahdavinejad, R., \& Solati, A. (2018). Surface hardness improvement in surface grinding process using combined Taguchi method and regression analysis. Journal of Advanced Mechanical Design, Systems, and Manufacturing, 12(2), 1-14, doi:https://doi.org/10.1299/ jamdsm.2018jamdsm0049

6. Patil, P. J., \& Patil, C. R. (2016). Analysis of process parameters in surface grinding using single objective Taguchi and multi-objective grey relational grade. Perspectives in Science, 8, 367-369. doi:http://dx. doi.org/10.1016/j.pisc.2016.04.077

7. Luu Anh Tung, Vu Ngoc Pi, Vu Thi Lien, Tran Thi Hong, Le Xuan Hung, Banh Tien Long. (2019). Optimization of dressing parameters of grinding wheel for $9 \mathrm{CrSi}$ tool steel using the taguchi method with grey relational analysis, IOP Conf. Series: Materials Science and Engineering, 635 (012030), 1-8, doi:10.1088/1757-899X/635/1/012030
8. Tran Thi Hong, Nguyen Van Cuong, Le Hong Ky, Nguyen Quoc Tuan, Banh Tien Long, Luu Anh Tung, Nguyen Thanh Tu, Vu Ngoc Pi. (2020), Multi-Criteria Optimization of Dressing Parameters for Surface Grinding 90CrSi Tool Steel Using Taguchi Method and Grey Relational Analysis, Materials Science Forum, 998, 61-68, doi:10.4028/www.scientific.net/ MSF.998.61

9. Aqib Mashood Khan, Muhammad Jamil, Mozammel Mia, Danil Yurievich Pimenov, Vadim Rashitovich Gasiyarov, Munish Kumar Gupta, Ning He. (2018), Multi-Objective Optimization for Grinding of AISI D2 Steel with $\mathrm{Al} 2 \mathrm{O} 3$ Wheel under MQL, Materials, 11(2269), 1-20, doi:10.3390/ma11112269

10. Prashant J. Patil, Chandrakant R. Patil. (2016), Optimization of process parameters of grinding operation using Taguchi based grey relation analysis, Proceedings in Manufacturing Systems, 11(1), 9-14.

11. Hendri Jumianto, Suhardjono, Sampurn, $M$. Khoirul Effendi. (2019), Multi-Response Optimization on Vibration and Surface Roughness of the Process Parameter Surface Grinding of OCR12VM Using Taguchi-Grey Method, AIP Conference Proceedings, 2187, 030015, 1-8, https://doi. org/10.1063/1.5138319

12. Gadakh. V. S. (2011). Application of MOORA method for parametric optimization of milling process, International journal of applied engineering research, Dindigul, 1(4), 743-758.

13. Mesran, Rivalri Kristianto Hondro, Muhammad Syahrizal. (2017). Andysah Putera Utama Siahaan, Robbi Rahim, Suginam, Student Admission Assesment using Multi-Objective Optimization on the Basis of Ratio Analysis (MOORA), 4th International seminar: Research for science, technology and culture, 1-7.

14. Nguyen Huu-Phan, Banh Tien-Long, Le QuangDung, Nguyen Duc-Toan, T. Muthuramalingam. (2019). Multi-Criteria Decision Making Using Preferential Selection Index in Titanium based Die-Sinking PMEDM, journal of the korean society for precision engineering, 36(9), 793-802, doi:https://doi. org/10.7736/KSPE.2019.36.9.793

15. Tran Trung Hieu, Nguyen Xuan Thao, Phan Trong Tien, Le Thi Minh Thuy. (2019). Application of MOORA and COPRAS Models to Select Materials for Mushroom Cultivation, Journal of Vietnam Agricultural Science and Technology, 17(4), 322-331. 
16. Zavadskas E.K., Kaklauskas A, Sarka V. (1994). The new method of multicriteria complex proportional assessment of projects, Technological and economic development of economy, 1(3), 131-139.

17. Edmundas Kazimieras Zavadskas, Jurgita Antucheviciene, Prasenjit Chatterjee. (2020). Multiple-Criteria Decision Making (MCDM) Techniques for Business Processes Information Management, information, MPDI, doi:https://doi.org/10.3390/ info10010004
18. Triantaphyllou, Evangelos. (2000). Multi-criteria Decision Making Methods: A Comparative Study, Springer - Science + Busines media. https://www. springer.com/gp/book/9780792366072

19. Brauers W.K.M. (2004). Optimization methods for a stakeholder society. A revolution in economic thinking by multi-objective optimization, Boston: Kluwer Academic Publishers 